\title{
Resilience and social cohesion through the lens of residents in a Kenyan informal settlement.
}

VERTIGANS, S. and GIBSON, N. 
Title page

Resilience and social cohesion through the lens of residents in a Kenyan informal settlement

Stephen Vertigans and Neil Gibson

Robert Gordon University

Aberdeen, UK, AB39 3YT

Contact: s.vertigans@rgu.ac.uk

Funding for this project was provided by Robert Gordon University from GCRF/ODA allocation. 


\title{
Resilience and social cohesion through the lens of residents in a Kenyan informal settlement
}

\begin{abstract}
Over recent years, resilient attitudes and behaviour are widely seen within the Global North to be potential solutions to community developmental challenges. Although greater international emphasis is being placed on 'bottom up' approaches, only limited attention has been placed on learning from existing levels of resilience among communities such as residents in informal settlements. Instead analysis of informal settlements tends to concentrate on the multitude of environmental, economic and social problems that many communities share and internationally derived normative solutions. To help address this relative neglect, research was designed that sought more information about local experiences, people and processes that have been instrumental in building levels of resilience that help overcome challenges and improve well-being. Using the photovoice methodological technique, a project was developed to capture experiences of participants in Kibera, Nairobi. Participants were young people and either role models or had the potential to be. In so doing the project was participant driven, learning from residents about who and what have been influential in the development and maintenance of resilience. The results highlighted the particular significance of social cohesion and, in particular, relationships and attachment to place.
\end{abstract}

\section{Key words}

Informal settlement, Kenya, Kibera, photovoice, resilience, social cohesion 


\section{Resilience and social cohesion through the lens of residents in a Kenyan informal settlement}

\section{Introduction}

Kenya has the largest economy is East Africa, is globally renowned for wildlife and exotic locations and has a growing population currently estimated to be 48.5 million (UNDP 2018). The country also has multiple fragile situations including natural disasters such as droughts and floods, processes of desertification, high levels of poverty and ethnic divisions (EC2013, UNDP2018). Most of these risks are prevalent within Kenyan informal settlements (Mitya et al 2017, Thieme 2013, Thorne et al 2015) where people show resilience, able to overcome difficulties in achieving personal and communal goals (Bennett et al 2015, Mitya et al 2017, Ombati and Ombati 2016). The importance of resilience to the community development of such fragile localities has become increasingly recognised within international applications (EC2013, HDR 2012). Folkema et al (2013:1) highlight this development when suggesting, 'resilience is now at the heart of development thinking, climate change adaptation and humanitarian policy'. This application across regions connects into Steiner et al's (2018: 101) observation, that there is "empowering" community led development which is key to improving the sustainability of disadvantaged regions and providing local people with the capacities to respond positively to change.' Yet within these approaches, implementation programmes tend to be based around Global North knowledge, insights and templates. As Brown (2016: 62) notes, in respect to many international policy documents, 'in each of them and in the discourses they represent, resilience is applied in a normative sense.' The UNDP (2014: iv) is a case in point. In seeking to address vulnerabilities and build resilience to future shocks the report outlines a number of highly improbable recommendations such as 'universal access to basic social services, especially health and education; stronger social protection; including unemployment insurance and pensions; and a commitment to full employment'.

Within a more descriptive understanding of resilience, research in this paper was designed to explore the resilience of people in Kibera, an informal settlement in Nairobi. At the onset it is important not to romanticise the location because residents live in environments with daily pressures on space, welfare, infrastructure and governance. Overcrowding is accompanied by poor housing and restricted access to heating, energy and sanitation (Thorn et al 2015). Health and educational facilities are underdeveloped with $60 \%$ of Kenyan youths under 21 illiterate or semi-literate (Chege and Mwisukha 2013) and informal settlements are associated with poverty, crime, violence, alcohol/substance abuse, gang membership and unemployment rates (Ombati and Ombati 2016, Thieme 2013). These pressures are exacerbated by an annual $2.5 \%$ national population growth that has the most significant impact upon informal settlements. For 
instance, in Nairobi, it is estimated that between $50 \%$ and $70 \%$ of the city's population of over three million people live in informal settlements (Mutisya and Yarime 2011, Elverson and Hoglund 2017).

In terms of population, Kibera is believed to be the largest settlement in East Africa. Because of the density of people and unreliable methods of data collation, estimates for the number of residents range from 250,000 to one million living in $2.2 \mathrm{~km} 2$ (Elverson and Hoglund 2017) or one square mile (Praszkier et al 2010) The location was selected as the basis for the fieldwork because of the range of deep rooted problems that are typical of challenges facing many Kenyan informal settlements. Moreover, Kibera witnessed considerable violence in the aftermath of the disputed 2007 general elections when around 1,300 people are believed to have been killed and up to 600,000 people were displaced across Kenya (Njogu 2011, Schuberth 2018).

Facing these social, economic, environmental and political difficulties, individuals and communities in informal settlements also evidence resilience and social entrepreneurship. In the fieldwork local participants referred to various initiatives such as learning, business, culture, health, welfare and sanitary facilities. Yet, picking up on Brown's (2016) earlier point, these local processes of adjustment and resolution are missing within normative accounts that focus on informal settlements' problems and external international solutions. There is, as O'Brien et al (2009) argued, a requirement to shift attention from globalised governance structures towards greater local autonomy and diversity. Hence better understanding of enabling and protective indigenous factors can help improve insights into how people living in poverty find the resilience to maintain and improve well-being while striving for sustainable community development, empowerment and self-reliance. Through the method of photovoice this project aimed to make a contribution towards improving levels of understanding about resilience and processes of social cohesion within Kibera.

\section{What is resilience?}

From early roots in areas of ecology, psychology, engineering and organisational management, Grove (2018) outlines how resilience applications have been extended to include international development, climate change, humanitarianism, community development and multiple academic disciplines. The growing prominence of resilience, Brown (2016) explains, arose in part through shifts in global responsibilities and neo-liberal contractions in welfare provision. Greater emphasis on market economies stripped away social supports while national governments and international institutions were ill-equipped to address rising concerns about climate change. 
Applying the concept of resilience has been influenced by different academic epistemologies resulting in a range of definitions and usages. This diversity is highlighted by Tierney's (2014) study into over 40 different uses of the concept in academic and professional literature. Within international applications of resilience, (social) ecological approaches systems models have become most dominant (Brown 2016, Grove 2018). Attention has been placed upon levels of disturbance to systems and the prevention, adaptability or adaptive capacity of the system to 'bounce back' and how resilience can be enhanced for future disasters. Such an approach is subjected to criticism from other disciplines, notably social scientists who point to the neglect of power, politics and agency and the failure to appreciate social relationships, processes and roles (Blewitt and Tilbury 2014, Hatt 2013). Moreover, the study of resilience needs to consider the complexities and unpredictability of daily life. Drawing on similar points (Brown 2016: 118) concludes that 'resilience [is shown] to be the site of social relations, struggles and dynamics, intricately connected to how societies work.' This emphasis on everyday social processes and interactions that help shape what Grove (2018: 34) describes as "permanent adaptability" to a turbulent environment' is applied within the social scientific approach adopted within this paper. Recognising the complexities of local, dynamic, interconnected processes further reinforces the requirement to engage local people. Detailed knowledge of such processes is beyond the grasp of outside experts who lack residents' insights into experiences, knowledge and networks that help shape their levels of resilience and the management of change. Hence in this paper, there is a striving to understand from residents about processes that incorporate individual and community group shaping of resilience within development. Information obtained from residents about key influences in what works and the sources for these influences can then be considered for what could be replicated or adapted within resilience building programmes in other locations.

In keeping with the way in which resilience is being applied, Hall and Lamont's (2013: 2) definition is adapted to the capacity to sustain and advance individual and communal wellbeing in the face of challenges. This definition is suited for the everyday resilience that is embedded within localised social processes and relationships that interplay with state level policies and gaps in provision.

Finally, in this section, it is important to acknowledge significant concerns that resilience becomes subservient to processes of neo-liberalism. In so doing, vulnerability becomes normalised with individuals and local communities held responsible for managing the impacts of wider economic, environmental, political and social constraints and changes (Blewitt and Tilbury 2014, Brown 2016, Grove 2018, Pugh 2014). The approach in this paper does not lose sight of the wider underlying causes of poverty, inequality or climate change that need to 
change to enable enhanced access to power, opportunities for greater justice and equality to strengthened and unsustainable development targeted. Cognisant of these counter processes, this paper is based on potential, within these constraints, for resilience to improve communal well-being, development prospects and empowerment that could help to transform community and state relations. And the potential for resilience is heavily influenced by layers of social cohesion.

\section{Protective and enabling social cohesion}

The extent to which resilience becomes prominent is influenced by a range of social processes and protective or enabling factors and interwoven social processes. These have been identified to lessen risk and/or encourage well-being that can be unique to particular places and different situations (Blewitt and Tilbury 2014). Garbarino and Kostelny (1996) and Sousa et al (2013) discovered that fortitude and resilience with individuals and communities are influenced by characteristics such as demographics of age and gender, internal resources such as hope, optimism, determination and religious convictions allied to the protective influences of community, work, school and political action. Other factors to consider include economic growth, stability of livelihoods and equitable employment opportunities that Godschalk (2003) and Norris et al (2008) highlight are integral to a resilient community.

A key requirement for community based resilience is social cohesion and the social support networks and communal engagement. The World Bank (2012:6) declares that,

social cohesion describes the nature and quality of relationships across people and groups in society, including the state. The constituency of social cohesion is complex, but at its essence social cohesion implies a convergence across groups in society that provides a framework within which groups can, at a minimum, coexist peacefully.

One developmental way forward is suggested by the UNDP (2014: 7) through,

changing norms to build tolerance and deepen social cohesion is also a necessary and often overlooked aspect of building resilience societies.

Nevertheless, there remains uncertainty about whether these processes should stem from and be disseminated by international institutions, that are ostensibly dominated by the Global North. HPG (2014) draw similar observations in noting the tendency to assume activities that enhance resilience in particular situations can be applied universally. And while these 
observations share long standing concerns about aid related development, an ambiguity remains surrounding what will be achieved, by whom and how. Such fundamental questions remain because implementation strategies have often not addressed how resilience is shaped for and by people based in fragile situations. This project was designed in part to address some of these questions.

Within informal settlements, cohesion contributes to communal resources, community engagement and social capital including consensual values and sense of place, pride, social control and togetherness (Forrest and Kearns 2001, Madonsela 2017, Mitya et al. 2017). Social relations bind the group together with their significance magnified during periods of difficulty and crisis when group members are motivated to contribute to social welfare (Cartwright 1968). Placing social cohesion at the centre of development efforts will help, the World Bank (2012) argues, to address fragility. In fragile areas different groups often require incentives to coexist that are based around trust and which are drawn out in the Kibera fieldwork. Because of the vulnerability of youths to shifting global processes of development (Golub and HansenLewis 2012, Human Development Report 2012) and in the Kenyan context disproportionately high unemployment young people were the focal point of this project.

\section{Methodology}

At the onset of the project, a number of potential methodological problems were considered. From the onset qualitative methods were considered the most appropriate, influenced by Ungar et al's (2007) approach to resilience to gain narratives of resilience, focus on capacities and strengths while recognising variations. Underpinning such epistemological questions was a fundamental concern about the dynamics between researchers and participants and the danger of imposing northern hemisphere interpretations onto complex social interactions and experiences in other parts of the world. Harris (2017) outlines how text based community based research exacerbates power relations between researchers and professionals, who devise the formats, and participants who often do not share the same terminology or experiences of the processes. These challenges are magnified when researchers and participants are from different socio-economic backgrounds and can be especially problematic when southern hemisphere locations and peoples are investigated by northern hemisphere academics. In this project, research techniques were explored that aimed to avoid as far as possible the imposition of northern hemisphere power structures, nor to assume universal relevance of knowledge or dominate processes of communication. An approach that can avoid these pitfalls while offering sensitivity and incisive insights has been developed by Minkler and Wallerstein (2011). They suggest that research into complex issues such as social, structural, and environmental factors can often be enhanced by adopting a community-based 
participatory research (CBPR) approach which could help overcome some of the projected difficulties. This technique views the research process as being one of collaboration between researchers and participants, specifically in the initial analysis of the gathered data. Because of the collaborative nature, CBPR is often described as an empowering process because participants are invited to take control of the research process and direct focus to the important and pertinent issues which impact upon them (Duffy, 2011). And this emphasis on empowerment ties in neatly with the potential of resilience to incorporate community development and engagement in building local capacity (Steiner et al 2018).

Information was collected from participants through photovoice, a CBPR methodological approach. This technique puts the participants in control of data collection and discussion while aiming to empower voiceless people (Vaneeckhaute et al 2017). Harris (2017: 3) explains how 'the method privileges the subjective experience of participants, using a wide angled and open-ended approach to generate participant-driven analysis of everyday life'. Marginalised groups gain greater control with the tools to create visual documentation of their experiences which have hitherto been neglected and often rarely accessed by researchers from outside the community. Bananuka and John (2014: 197) explain 'photovoice methodology facilitates ... participant reflection'. And the nature of this process can result in risks associated with identifying sensitive issues. In this project to help address this risk, support structures, such as a counsellor, were available but were not required.

The photovoice approach draws upon theories informing visual ethnography and short term ethnography, (Pink, 2013; Wang 1999, Wang et al 1997). By using these methods, participants should feel empowered to explore their own issues and environments in order to learn about collective issues whilst also educating others (Hlela 2016). Because of the open ended approach as Harris (2017: 3) notes, findings do not lend themselves to large-scale generalization 'but is useful for building participant-driven practical theory about how environments impact [on] everyday people'.

Nineteen young people were recruited for the project. All lived in Kibera and belonged to three local Community Based Organisations (CBOs) who were instrumental in selecting participants. The CBOs were selected because they can be, as e-Ogbuafor et al (2016: 174) explain, 'agents of bottom-up CD [community development] because they entail community members initiating and driving their own development'. The main criteria for involvement of individuals was that they should be positive role models or have evidenced the potential to be. Crucial to the process was the local facilitator who both lived in Kibera and was a student at the local university that was the base for the sessions. His responsibilities included identifying CBOs, potential contributors, inviting them to participate in the project and on occasion translating 
into Kiswahili and Sheng languages. Because the intention was to investigate resilience in people who could be considered mentors the sampling for this project was purposive. Eighteen participants remained at the end of the project, nine females and nine males.

At the introductory session participants were issued with camera-phones to photographically record and represent factors that affected their resilience. Mobile phone technology was chosen over cameras because they were deemed to be less of an anomaly within the community where mobile phone use is very common. By comparison using a camera would be more intrusive. Moreover, the phone was also expected to be of greater longer term benefit to participants after the project ended.

To begin, participants attended a training course spread over three days to learn both how to use the equipment and how visuals can help explore issues. Sessions also addressed matters pertaining to participant consent and confidentiality. Because of sensitivities surrounding some potential images and interpretations, considerable emphasis was placed upon possible risks and how these can be minimised. With input from the student resident, there was a discussion around resilience. Researchers outlined how the development of the concept had largely been applied within the Global North and explained how the concept was intended to be adapted in this project. Everyday and event specific resilience was mentioned and the group debated relevance to their lives. After recognising the suitability of the concept in Kibera, participants were asked to photograph subjects, objects and people around the general theme of resilience, namely who or what represents resilience in Kibera. With respondents unlikely to have internet access, a virtual site was established specific to the project with training and access provided. After four weeks, researchers returned to Nairobi bringing copies of the photographs that had been submitted to the designated site. From these images participants selected four photographs which were most representative of resilience in Kibera. In small workshops individuals were asked to explain the significance of their photographs. These sessions were recorded and subsequently transcribed. Based upon these transcriptions, themes were identified that participants raised in connection with the photographs. Subsequently reflective quotes were applied to the themes and photographs in order to underpin the results with the participants' voices.

Following data analysis, feedback sessions were organised for leaders from the three participating organisations and five of the participants. These sessions were designed to discuss provisional findings, to establish whether impressions were shared and to gain further insights. The feedback both on the analysis and recommendations helped to refine the analysis and strengthened recommendations which have been reported to the relevant Kenyan Ministry. 


\section{Results}

The formation of the principle themes and accompanying photographs and narrative brought rich, vivid visual and oral insights into influences and obstacles in developing and strengthening resilience in Kibera. A range of complex, interwoven relationships and activities were raised.

\section{Sense of belonging and identification}

Throughout the discussions and across the submitted images there was a common sense of belonging and strong sense of pride in where the participants were from. For instance, figure 1 captured this sense of belonging, with graffiti forming a panoramic landscape against the open sewer and piles of rubbish, welcoming outsiders to the area.

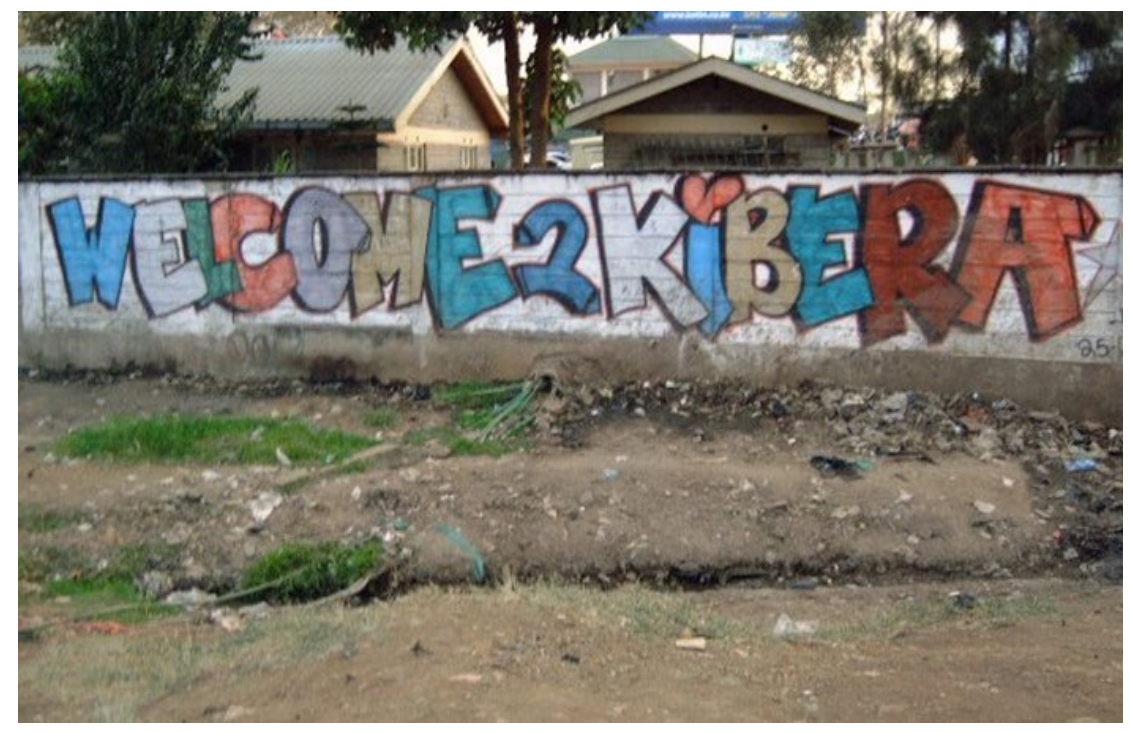

Fig 1 - Pride of neighbourhood

When this observation was explored the following statements were indicative,

'In spite [of difficulties] we love the place where we come from'.

'There is much love here, there is much happiness'.

'If you walk down the road you will see people smiling at each other'.

Participants did not seek to idealise place and highlighted negative aspects of the location that tend to be visually evident. Nevertheless, they also emphasised that people who lived within the environment were instrumental in many positive aspects of life in Kibera. There were strong feelings of love, loyalty and belonging, a sense of identity which was rooted in the 
geography of the settlement. These connections with Kibera rather than Nairobi reflect Gordon's (2016) research into urban resilience in Managua, Nicaragua that noticed that residents tended to identify with neighbourhoods rather than city. This sense of identity and place, beliefs and knowledge can, Brown (2016) argues characterise local resilience. Forrest and Kearns (2001: 2135) point out how 'external perceptions of areas impact on the behaviour and attitudes of residents in ways which may reinforce cohesive groupings and further consolidate reputations'. Alongside these shared insights, important distinctions are drawn by residents. For instance, a couple of villages in Kibera are referred to as 'middle class' and other parts are described as the 'slum within the slum'. Divisions within Kibera have also formed around property rights and between landlords who tended to be Nubians and Kikuyus and tenants who are more likely to belong to other groups. During the 2007/08 post-election violence, these tensions became inflamed and contributed to murderous attacks, the destruction of property and eviction both of landlords and tenants (De Smedt 2009, Kihato 2015).

The view of Kibera held in neighbouring communities and across Nairobi tends to focus on stereotypes and ill-informed perceptions of risk such criminal violence, election related conflict, corruption and poverty (Mitya et al. 2017, Osborn 2008, Schuberth 2018). In turn these perceptions help shape participant connections with their place. There was also recognition in the Kibera study that place shaped life skills and aspirations.

\section{Relationships - Family}

The significance of bonds was evident in the discussions referring to the family and many images captured the cohesion of interactions between family members.

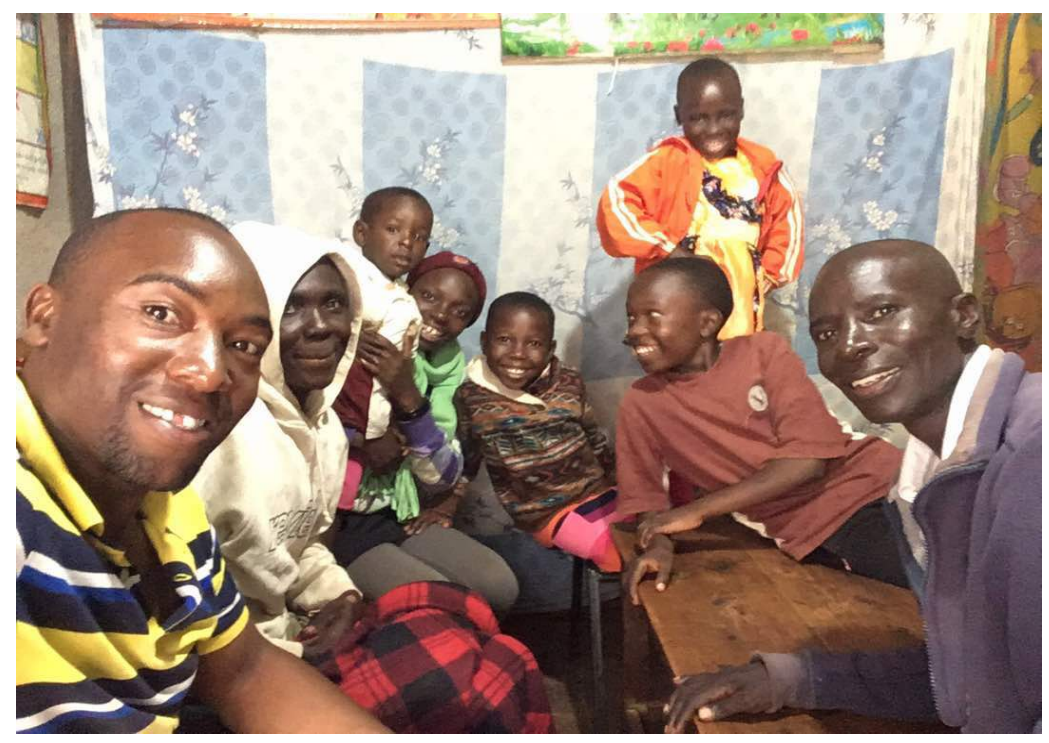

Fig 2 - Intergenerational family 
The prevalence of family was noted by all participants and reflected upon within focus groups. Some participants used this opportunity to consider previous hardships that the family had experienced, and how this underpinned motivation and sacrifices for their children. In turn, this motivation appeared to be linked to entrepreneurial drive to try ensure that participants' children will avoid the same difficulties. And on the reverse of advancement is survival, and daily searching for the essentials of life such as food and fuel,

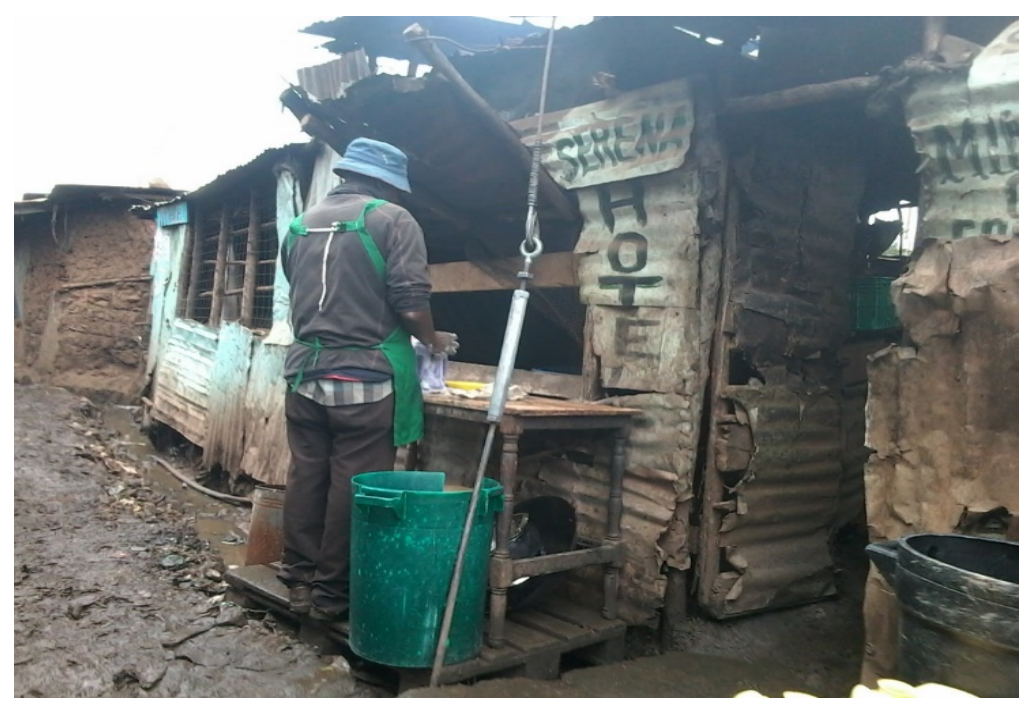

Fig 3 - Man working at food stall: 'This man is hustling for his family because ... he had to work hard ... to get something at the end of the day'.

Within discussions, participants explained the need to leave the house at the start of the day with a purpose to return with something at the end of the day, underpinned by a drive to provide for the family. Returning empty handed was seen to be failing the family. And the pressure to avoid failing the family was a key driver for participants. As Dorff (2017: 4) explains, in relation to Latin America, there is long standing evidence 'that family networks specifically play a critical role in how individuals respond to insecure environments'.

Relationships - People needing each other

Kibera is a large community, and participants outlined how they drew strength from those around them. Networks of extended family members, neighbours, and friends all appeared to provide vital support. Photographs conveyed the closeness amongst community. 


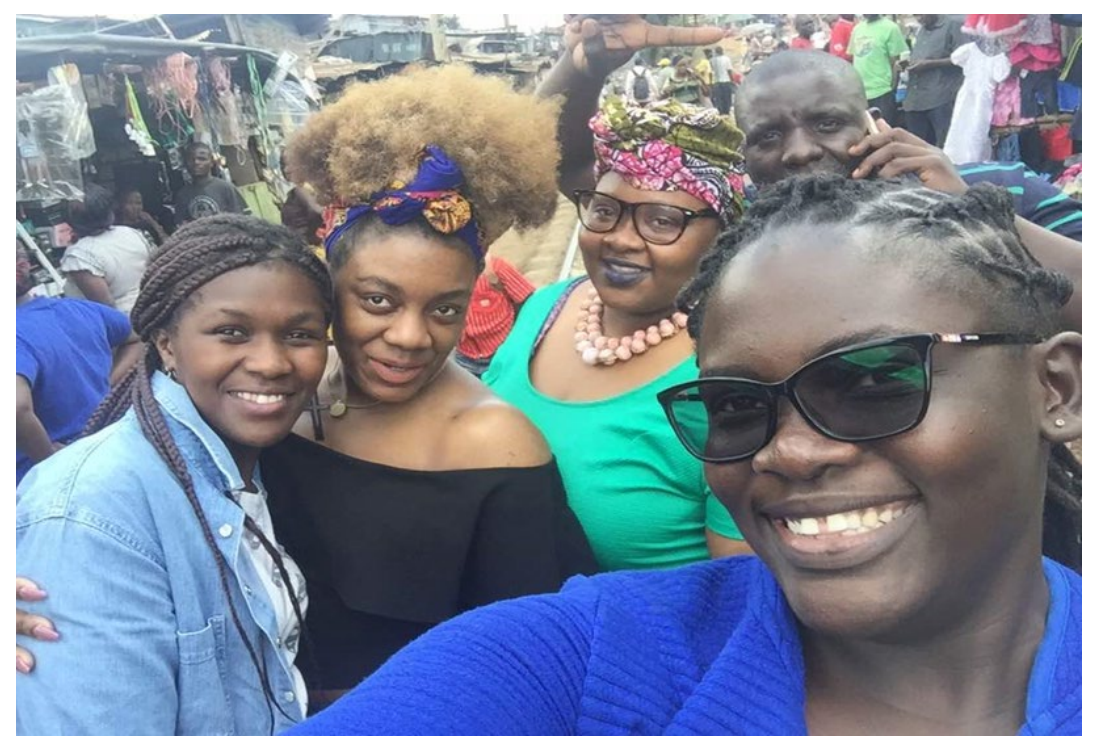

Fig 4 - Participants with friends

Within focus group discussion there was a sense that community strength and support was a normal aspect of life, that need could be addressed through support from those around you. There was also a sense of community responsibility and duty to teach future generations about the importance of helping each other. This emphasis on helping across generations was illustrated in some of the images which captured young children engaged in tasks.

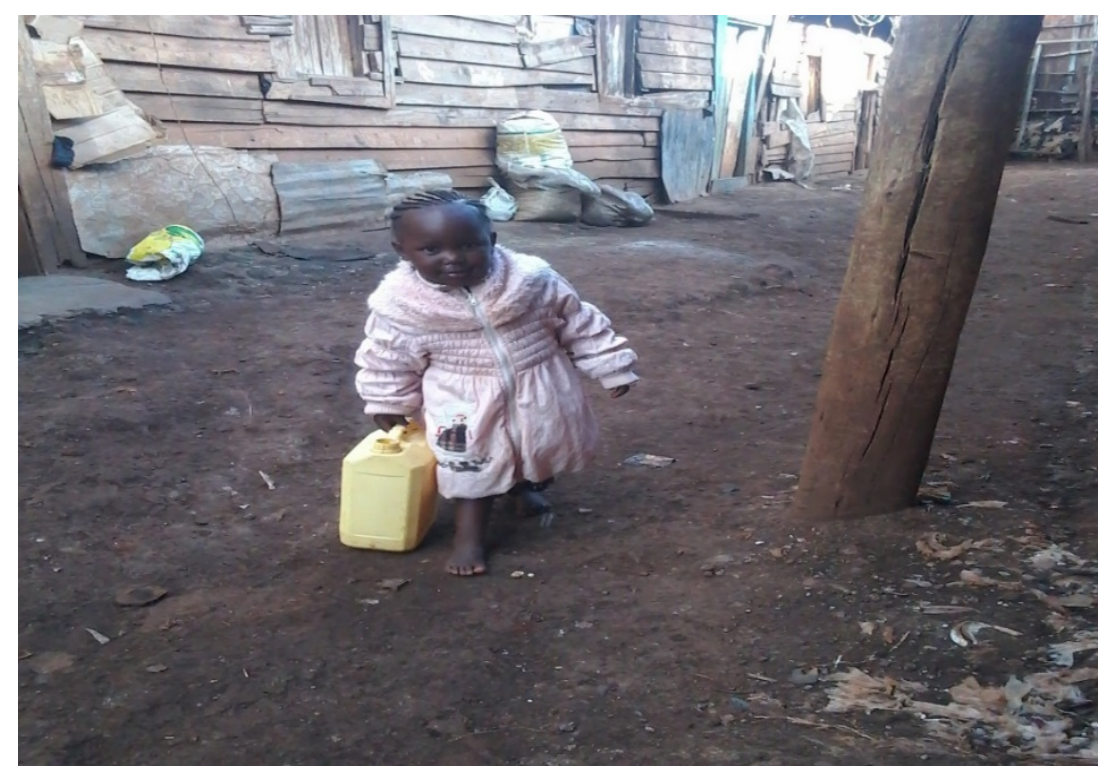

Fig 5 - A young child helping with domestic chores

Relationships and social cohesion 
Following on from the above observations and the preceding discussion about the significance of social cohesion for resilience, the main focus of relationships was around drawing happiness and strength from others. However, there was also recognition that continued survival was dependent on these social links. And the clarity of social roles is such that from an early age children become unconsciously committed to the maintenance of, and connected to, the family and by extension the community.

When asked in the concluding feedback sessions about the most important relationships, family and friends dominated both in providing, and receiving, support. There were also distinctions drawn between gender roles. Male contributions were often considered to be negative, ranging from no familial commitment to too much focus on earning money for the family, expressed as,

'Mother, father does not really work well. The family needs more than one strand of income. Pressure is also on man to provide for family so they spend lot of time out of house. Perception of the wife is that "you are always working, you always leave job of children and home to me". The perception of the man is that have to get money which pulls them from the family. Then if they don't get enough money they are under pressure. If they do not then they drink or turn to violence in the home against woman and children. And those who are working work so much that they lose sight of what they are working for'.

By comparison, female roles were considered to be more enabling and protective. When discussing who was influential in resilience a different participant suggested, contrary to the perceived threat of young people in informal settlements, that,

'it has been strengthened by the youth groups. Youths come together even if they do not have the resources'.

Moreover, the ties within Kibera were seen to retain peoples' attachments even after leaving the area. For instance, following a government resettlement scheme some,

'people who moved to better housing moved back for common friendship. Good neighbours are really good. They watch out for your house'.

In another feedback session,

'you have to trust your neighbour. Because when you are not at home your neighbour is the one who looks after your house when you are not around. So you 
have to trust your neighbour because you are not going to stay in your house for ever. You have to step out for something ... our neighbours are our eyes. Check if everything is ok....'

Neighbours also featured for other participants who noted that,

'When we have a problem we can solve the problem together. There is no divide between people, you must share with your neighbour.'

While another resident mentioned,

'I think that we come together as in Kibera the houses are too small so you just have to talk to your neighbour. You see your neighbours' doings. It is not like you people. When you reach your neighbour it is like one metre and you might find in your house you do not have salt .... there is that connection.'

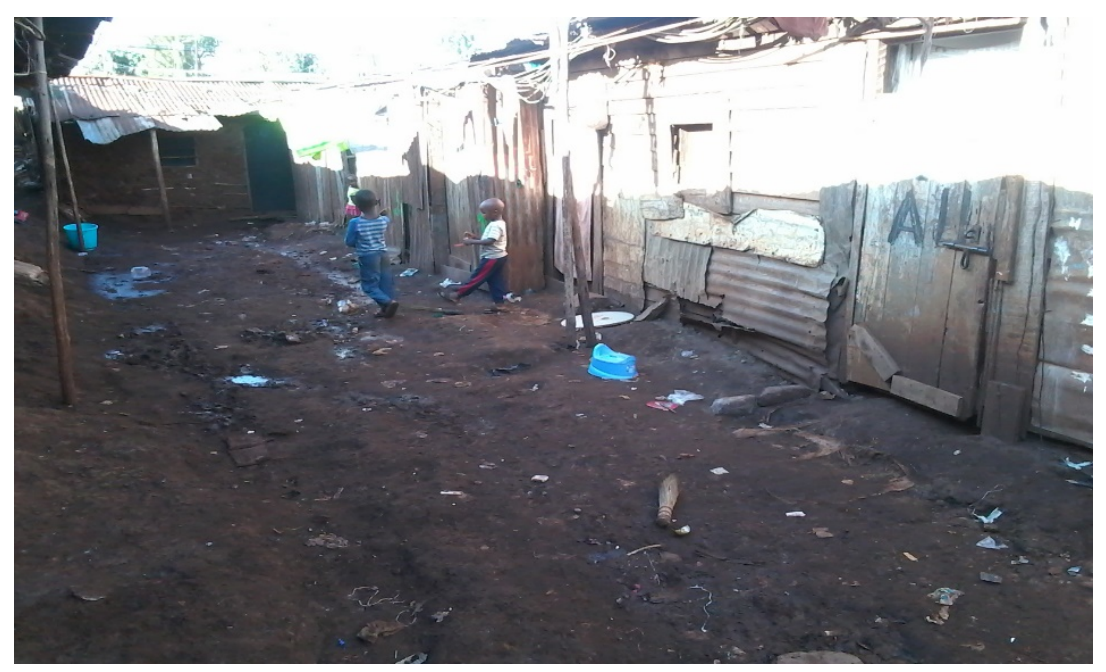

Fig 6 - Boys playing in the neighbourhood

In one workshop the sense of commitment and communal resilience is extended to newly arrived residents was outlined,

'We have neighbour who just moved in and she was pregnant. And she was due and then all she needed was to scream and everyone was ready. Within three minutes she was being taken to neighbouring hospital.' 
During the subsequent discussion the researcher suggested that other parts of Nairobi may not have the same level of support and attachment as Kibera and comparison was drawn with Westlands, one of the most prestigious parts of the city. A participant explained,

'in Westlands those people have made it in life so that they have that pride. It is me, myself and my family.... Every man for himself. But in Kibera we need each other, every step you make you need someone. Everything you need to succeed you need someone, But for them they feel they have already made it. They don't need each other. So that is the difference from the people of Kibera and the Westlands people.'

This emphasis on the role of neighbours was a feature of the feedback sessions, drawing together emotional attachments, trust and the pragmatic benefits to resilience that such ties provided. Local people tend to spend the majority of their time within Kibera and as such their networks often have a concentrated radius. And as Forrest and Kearns (2001: 2130) explain in what they describe as 'disadvantaged neighbourhoods' 'it maybe that the quality of neighbouring which is an important element in peoples' ability to cope with a decaying and unattractive physical environment'. By comparison in places like Westlands, the neighbourhood is more important than what they refer to as 'neighbouring'.

Trust had already been shown to be integral within the reported relationships. When asked to elaborate on the basis for trust, comments were put forward such as,

'Usually there is trust, trust and trust. It is almost like it is too expensive not to trust. There is the need. I know if I help her today tomorrow she will help me. Referrals work very well in this. We rely on intuition and have to trust. The other way is to counter a bad person. If you have a thief as a friend they are less likely to steal from you.'

And another participant suggested that,

'Trust is based on personal interests ... That will depend on aspect of relationships, am I related, are you my friend? Also based on experiences. If someone did not help before or their organisation then will not try this again [and] 'If [the person] support same football team, Manchester United, Chelsea then that is shared and might influence if they think he supports my team'. 


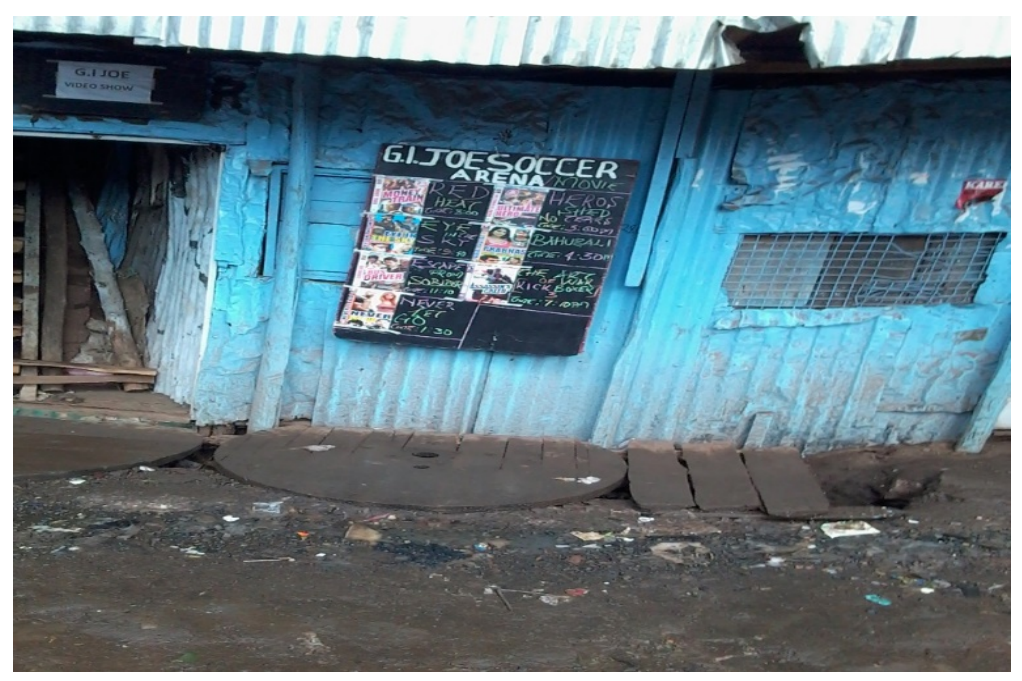

Fig 7 - Venue where live football is shown

The centrality of mutual trust to ontological security was evident in the ways and manner in which the concept was applied, namely as a necessary precondition for Kibera's relationships and resilience. This 'deep trust' that Putnam (1995) describes is embedded within personal relationships and situations. Moreover, reciprocal trust and accompanying norms can provide the base for social capital that cuts across divisions and differences around ethnicity, gender and politics. Although as Adger (2003) and Levien (2015) has pointed out in his critique of Putnam (1995), that social trust can be exploited, in Kibera there is also the opportunity to build upon existing levels within neighbourhoods.

As the above football example indicated, sport was considered to be integral in community bonds for men. By comparison,

'for women it could be chama, merry go round. [Researcher: can you explain?] Every month you go to a friend's house and bring an agreed amount of money ... . The money can be used how the friend wants such as buy foodstuffs for my family. They have rules and stuff like that. [Researcher who becomes a member?] They are friends or a member can refer you. The member is responsible for them and if they are bad person the member is responsible for the person. So you should know anyone you refer really well. If you look like bad person then they won't let you'.

And when participants were asked, in relation to the above example of the pregnant woman, why the community was so supportive of someone they did not know, the response was, 
'Just when you are living you Kibera we say Kibera is like a university. So we say am my brother's keeper. So this time it is my time. So this time she needs my help, I had to be there for her. But she has to be there for me to be there for her. And that is what keeps us going.'

\section{Conclusion: 'People in Kibera make Kibera'}

The concluding sub title is a quote that is indicative of the widespread perception amongst the participants. This ownership and connection with developments in Kibera and sense of achievements underpin capabilities and capacity to be resilient when encountering daily and event specific uncertainties and challenges. Participants' consistent message across the fieldwork is that community based, rather than external, support services, have proved more effective in increasing levels of localised resilience. Existing relations and dynamics can be better suited to enable more effective coping in difficult situations. However, this observation is not to propose that more support will not be beneficial nor that all problems can be addressed within Kibera. The massive infrastructural obstacles and wider structural conditions and constraints that continue to restrict opportunities to build local resilience were not the primary focus of this project. Instead participants stressed the need for more locally achievable changes such as focused, relevant mentorship and training that would aid local sustainable solutions.

The community base for participants' levels of resilience stems, at least in part, from social cohesion and the type of relationships that people have and their exposure to influential figures at key stages in their development, often family members and friends. Through these relationships and wider networks people are able to connect into local knowledge, social capital and resources that help enable opportunities to be taken and obstacles overcome. In so doing people adapt and create everyday routine in the face of frequent challenges. Hence these adjustments are localised, social interactions within complex, multi-layered processes that are central to the creation and maintenance of resilience in Kibera.

Communal cohesion is embedded within processes of resilience that interconnect individual contributions to community wellbeing which in turn provide senses of personal purpose and satisfaction. The involvement of residents within community engagement create resources for tangible and intangible benefits both during day to day difficulties and to offset particular crisis and challenges. And the entwining of individuals and community strengthens collective senses of attachment and feelings of mutual interdependence that are instrumental in processes of resilience with Kibera. 
Moreover, the communal cohesion within Kibera and collective sense of identification provides the base for emotional attachment to both people and place. And although participants express their connections in powerful emotive terms such as love and happiness, these are emotions interwoven with pragmatism. These attachments are rooted in reciprocal reliance on other people who collectively help to protect, maintain and contribute to social well-being and individual security.

The fieldwork has been influenced by reservations about the appropriateness of the Global North ways of thinking, including the concept of resilience, within a Global South location. Adopting photovoice helped overcome some of these difficulties. And having discussed the purpose of resilience to the participants, there was resident adoption in applying the concept to capture community approaches to overcoming challenges. Nevertheless, on reflection, it is unclear if the concept felt owned by participants or was used principally because resilience was known to be central to the project.

In summary, exploring processes of resilience enables greater understanding into how individuals and marginalised communities encounter and overcome everyday challenges and event led crises. Facing high levels of poverty and mortality, low educational standards, endemic violence and absent public services, there are multiple examples of Kiberan resilience. These examples are underpinned by significant levels of social cohesion, relationships and activities on which hope, security and wellbeing are being sustainably developed.

Consequently, when devising development programmes for building resilience in similar contexts, lessons could be learnt. However, these are locally created social resources that enable Kiberans to maintain and improve well-being. Consequently, other research and development programmes need to consider levels of social similarities before potentially applying or adapting to other informal settlements.

\section{$\underline{\text { References }}$}

Adger, N. (2003) Social Capital, Collective Action, and Adaptation to Climate Change, Economic Geography, 79 (4), 387-404.

Bananuka, T and John, V. (2014) Picturing Community Development work in Uganda: Fostering dialogue through photovoice, Community Development Journal, 50 (2), 196-212.

Bennett, R., Chepngeno-Langat, G., Evandrou, M., and Falkingham, J. (2015) Resilience in the face of post-election violence in Kenya, Social Science and Medicine, 128: 159-167.

Blewitt, J. and Tilbury, D. (2014) Searching for Resilience in Sustainable Development, Abingdon: Routledge.

Brown, K. (2016) Resilience, Development and Global Change, Abingdon: Routledge.

Cartwright, D. (1968) The nature of group cohesiveness in Cartwright, D. and Zander, A, (eds), Group Dynamics: Research and Theory, London: Tavistock, 91-109. 
Chege, P. W., \& Mwisukha, A. (2013) Benefits of slum tourism in Kibera slum in Nairobi, Kenya. International Journal of Arts and Commerce, 2 (4), 94-102.

Dorff, C. (2017) Violence, kinship networks, and political resilience: Evidence from Mexico, Journal of Peace Research, 54 (1), 1-16.

Duffy, L. (2011) "Step-by-Step We are Stronger": Women's Empowerment Through Photovoice, Journal of community health nursing, 28 (2), 105-116.

European Commission (2013) KENYA -Supporting Horn of Africa Resilience in Kenya, European Commission. Available at: https://ec.europa.eu/europeaid/kenya-supporting-horn-africaresilience-kenya-share\%E2\%80\%93kenya en (last accessed 1 December 2018).

Elfversson, E. and Hogland, K. (2017) Home of last resort: Urban land conflict and the Nubians in Kibera, Kenya, Urban Studies, 53(1): 1-16.

Folkema, J., Ibrahim, M. and Wilkinson, E. (2013) World Vision's resilience programming; Adding value to development, London: World Vision.

Forrest, R. and Kearns, A. (2001) Social cohesion, social capital and the neighbourhood, Urban Studies, 38 (12), 2125-2143.

Garbarino, J. and Kostelny, K. (1996) The Effects of Political Violence on Palestinian Children's Behavior Problems: A risk accumulation model, Child Development, 67 (1). 33-45.

Godschalk, D. R., (2003) Urban Hazard Mitigation: Creating Resilient Cities, Natural Hazards Review, 4 (3), 136-143.

Golub, S. and Hansen-Lewis, J. (2012) Informal Trading Networks in West Africa: The Mourides Of Senegal/The Gambia And The Yoruba Of Benin/Nigeria. World Bank, The Informal Sector in Francophone Africa: Firm Size, Productivity, And Institutions. 173-193. Available at: https://openknowledge.worldbank.org/handle/10986/9364 [last accessed 14 June 2018].

Gordon, R. (2016) Urban resilience in situations of chronic violence: Case study of Managua, Nicaragua. Available at:

https://www.researchgate.net/publication/266010515 Urban Resilience in Situations of Chronic Violence Case Study of Managua Nicaragua (last accessed 6 June 2018).

Grove, K. (2018) Resilience, Abingdon: Routledge.

Hall, P. and Lamont, M. (2013) Social Resilience in the Neoliberal Era, Cambridge: Cambridge University Press.

Harris, J. (2017) Vulnerable Youth's Perspectives and Priorities for Informal Settlements: Photovoice evidence from Lusaka, Zambia, Journal of Planning Education and Research, 37 (1), 1-15.

Hatt, K. (2013) Social attractors: A proposal to enhance 'resilience thinking' about the social, Society and Natural Resources, 26(1): 30-43.

Hlela, Z. (2016) Learning through the action of research: reflections on an Afrocentric research design, Community Development Journal, 53 (2), 375-392.

Kihato, C. W. (2015) "Go back and tell them who the real men are!" Gendering our understanding of Kibera's post-election violence. International Journal of Conflict and Violence, 9(1), 12-24.

Levien, M. (2015) Social Capital as Obstacle to Development: Brokering land, norms and trust in rural India, World Development, 74 (1), 77-92.

Luthar, S. \& Cicchetti, D. (2000) The Construct of Resilience: Implications for interventions and social policies, Development and Psychopathology, 12 (4), 857-885. 
Madonsela, S. (2017) Sociological perspectives on social cohesion as the principal requirement for social stability, South African Review of Sociology, 48 (3), 84-98.

Minkler, M. \& Wallerstein, N. (2011) Community based participatory research for health: From process to outcome, John Wiley \& Sons, NJ.

Mitya et al, (2017) Developing risk or resilience? Effects of slum upgrading on the social contract and social cohesion in Kibera, Nairobi, Environment and Urbanization, 29 (1), 103122.

Mutisya, E. and Yarime, M. (2011) Understanding the Grassroots Dynamics of Slums in Nairobi: The Dilemma of Kibera Informal Settlements. International Transaction Journal of Engineering, Management, \& Applied Technologies, 2 (2), 197-213.

Njogu, K. (2011) Defining Moments: Reflections on citizenship, violence and the 2007 general elections in 2007, Nairobi: Twaweza Communications.

Norris, F., Stevens, S., Pfefferbaum, B., Wyche, K. and Pfefferbaum, R. (2008) Community Resilience as a Metaphor, Theory, Set of Capacities, and Strategy for Disaster Readiness, American Journal of Community Psychology, 41 (1-2), 127-150.

O'Brien, K, Hayward, B. and Berkes, F. (2009) Rethinking social contracts: Building resilience in a changing climate, Ecology and Society, 14(2): 12.

Okeke-Ogbuafor, N., Gray, T. and Stead, S.M. (2016) A comparative analysis of the role of modern community-based organizations in promoting community development in Ogoniland, Nigeria, Community Development Journal, 53(1): 173-189.

Ombati, M. and V. Ombati (2016) Sources of resilience for children and youth in residential slums of Eldoret city in Kenya, Chinese Sociological Dialogue, 1(1): 48-65.

Osborn, M. (2008) Fuelling the Flames: Rumour and politics in Kibera, Journal of Eastern African Studies, 2(2), 315-327.

Pink, S. (2013) Doing visual ethnography, London: Sage.

Pugh, J. (2014) Resilience, complexity and post-liberalism, Area, 46 (3), 313-319.

Putnam, R. (1995) Bowling Alone: America's declining social capital, Journal of Democracy, 6 (1), 65-78.

Schuberth, M. (2018) Hybrid security governance, post-election violence and the legitimacy of community based armed groups in urban Kenya, Journal of Eastern African Studies, 12(2), 386-404.

Sousa, C., Haj-Yahia, M., Feldman, G. and Lee, J. (2013) Individual and Collective Dimensions of Resilience within Political Violence, 14( 3), 235-254.

Steiner, A., Woolvin, M., and Skerratt, S., (2018) Measuring community resilience: developing and applying a 'hybrid evaluation' approach, Community Development Journal, 53 (1), 99118.

Thieme, T., (2013) The "hustle" amongst youth entrepreneurs in Mathare's informal waste economy, Journal of Eastern African Studies, 7(3): 389-412.

Thorn, J., Thornton, T. and Helfgott, A. (2015) Autonomous adaptation to global environmental change in peri-urban settlements, Global Enivronmental Change, 31: 121-131.

UNDP (2014) Human Development Report: Sustaining Human Progress: Reducing vulnerabilities and building resilience, New York: United Nations Development Programme. 
UNDP (2018) Country programme document for Kenya (2018-2022) Available at http://www.ke.undp.org/content/dam/kenya/docs/UNDP\%20Reports/CPD\%2020182022.pdf (Last accessed 28 November 2018)

Ungar, M., Brown, M., Liebenberg, L., Othman, R., Kwong, W., Armstrong, M., and Gilgun, J. (2007) Unique pathways to resilience across cultures, Adolescence, 42(166), 287-310.

Vaneeckhaute, L.E., Vanwing, T., Meurs, P., Abelshausen, B., and Jacquet, W. (2017) Community capitals of a Pamaca Maroon village in pictures: a Photovoice study on community resilience in the context of large-scale gold mining, Community Development Journal, 1-21.

Wang, C.C. (1999) Photovoice: A participatory action research strategy applied to women's health. Journal of Women's Health, 8 (2), 185-192.

Wang, C., Yuan, Y. and Feng, M. (1996) Photovoice as a tool for participatory evaluation: The community's view of process and impact, Journal of contemporary health, 4 (1), 47-49.

World Bank, (2012) Societal Dynamics and Fragility: Engaging societies in responding to fragile situations, Washington: The World Bank Group. 